\title{
Silviano Santiago: o intelectual desobediente (trans)fronteiriço
}

\author{
Silviano Santiago: el intelectual desobediente (trans)fronterizo \\ Silviano Santiago: the disobedient (trans)frontier intellectual
}

Pedro Henrique Alves de Medeiros ${ }^{1}$

Edgar Cézar Nolasco 2

\begin{abstract}
Resumo
Este trabalho tem por objetivo refletir acerca da figura do intelectual Silviano Santiago à luz da crítica biográfica fronteiriça cunhada por Edgar Cézar Nolasco a partir da confluência dos estudos pós-coloniais (MIGNOLO, 2003) aos crítico-biográficos (SOUZA, 2002) (SOUZA, 2011) tomando como lócus enunciativo, tanto epistemológico quanto geoistórico, a fronteira-Sul do Brasil com os países lindeiros Paraguai e Bolívia. É segundo essa óptica teórica que buscaremos discutir a figura do crítico, homossexual e escritor mineiro partindo da premissa de que sua carreira/obra/vida se aquilatam em uma percepção (trans)fronteiriça por excelência. Essa alcunha se justifica através do trânsito crítico-ficcional-teórico e da visada epistemológica pós-colonial que atravessa as percepções de Silviano Santiago sobre a cultura e literatura brasileiras, seja tratando do outro ou exercendo sua escritura literária: exercícios sempre permeados pelo bios do menino natural de Formiga intelectualizado em Belo Horizonte. Para sustentar o debate proposto, nos assentaremos, dentre outros, em pesquisadores e obras como Histórias locais/projetos globais (2003) e "Desobediência epistêmica" (2008) de Walter Mignolo, Perto do coração selbaje da crítica fronteriza (2013) e "Crítica biográfica fronteiriça (Brasil/Paraguai/Bolívia)" (2015) de Nolasco, Janelas indiscretas (2011) de Souza, O local da cultura (2013) de Homi K. Bhabha, Planetas sem boca (2006) de Hugo Achugar e Representações do intelectual (2005) de Edward W. Said.
\end{abstract}

Palavras-Chave: Crítica biográfica fronteiriça; Desobediência epistêmica; Epistemologia fronteiriça; Silviano Santiago.

\section{Resumen}

Este trabajo tiene por objetivo reflexionar acerca de la figura do intelectual Silviano Santiago bajo la luz de la crítica biográfica fronteriza acuñada por Edgar Cézar Nolasco a partir da confluencia de los estudios poscoloniales (MIGNOLO, 2003) a los crítico-biográficos (SOUZA, 2002) (SOUZA, 2011) tomando como locus enunciativo, tanto epistemológico cuanto geohistorico, la frontera-Sul de Brasil con los países linderos Paraguay y Bolivia. Mediante esta óptica teórica, discutiremos la figura del crítico, homosexual y escritor mineiro partiendo de la premisa de que su oficio/obra/vida se aquilatan en una percepción (trans)fronteriza por excelencia. Esa designación se justifica a través del tránsito crítico-ficcional-teórico y de la visada epistemológica poscolonial que atraviesa las percepciones de Silviano Santiago sobre a cultura y literatura brasileiras, sea tratando del otro o ejerciendo su escritura literaria: ejercicios siempre permeados por el bios del chavo natural de Formiga intelectualizado en Belo Horizonte. Para sostener el debate propuesto, nos asentaremos, entre otros, en pesquisidores y obras como Histórias locais/projetos globais (2003) y "Desobediência epistêmica" (2008) de Walter Mignolo, Perto do coração selbaje da crítica fronteriza (2013) y "Crítica biográfica fronteriza (Brasil/Paraguai/Bolívia)" (2015) de Nolasco, Janelas indiscretas (2011) de Souza, O local da cultura (2013) de Homi K. Bhabha, Planetas sem boca (2006) de Hugo Achugar y Representações do intelectual (2005) de Edward W. Said.

\footnotetext{
${ }^{1}$ Graduado em Letras Português/Inglês; Núcleo de Estudos Culturais Comparados - NECC UFMS; Campo Grande, Mato Grosso do Sul, Brasil; pedro_alvesdemedeiros@ hotmail.com

${ }^{2}$ Doutor em Literatura Comparada; Núcleo de Estudos Culturais Comparados - NECC UFMS; Campo Grande, Mato Grosso do Sul, Brasil; ecnolasco@uol.com.br
} 
Palabras clave: Crítica biográfica fronteriza; Desobediencia epistémica; Epistemología fronteriza; Silviano Santiago.

\begin{abstract}
This work aims to reflect on the figure of the intellectual Silviano Santiago in the light of the biographical critique frontier, coined by Edgar Cézar Nolasco from the confluence of the postcolonial studies (MIGNOLO, 2003) to the biographical critics (SOUZA, 2002) 2011), taking as an enunciative locus, both epistemological and geo-historical, the southern border of Brazil with the neighboring countries Paraguay and Bolivia. It is according to this theoretical point of view that we will try to discuss the figure of the critic, homosexual and writer from the beginning of the career/work/ life perspective in a (trans)border perception par excellence. This nickname is justified through the critical-fictional-theoretical transit and the postcolonial epistemological perspective that crosses the perceptions of Silviano Santiago on Brazilian culture and literature, whether dealing with the other or exercising his literary writing: exercises always permeated by the boy's bios native of Ant Intellectualized in Belo Horizonte. In order to support the proposed debate, we will be based, among others, on researchers and works such as Histórias locais/projetos globais (2003) and "Desobediência epistêmica" (2008) by Walter Mignolo, Perto do coração selbaje da crítica fronteriza (2013) and "Crítica biográfica fronteiriça (Brasil/Paraguai/Bolívia)" by Nolasco, Janelas indiscretas (2011) by Souza, O local da cultura (2013) by Homi K. Bhabha, Planetas sem boca by Achugar and Representações do intelectual (2005) by Edward W. Said.
\end{abstract}

Keywords: Frontier biographical critique; Epistemic disobedience; Frontier Epistemology; Silviano Santiago.

O mundo acontece pela diferença e é uma diferença altamente politizada (SILVIANO, 2016). São dessas palavras que o poeta, contista, romancista, professor, crítico e intelectual mineiro Silviano Santiago se utiliza para descrever sua experiência enquanto latinoamericano, brasileiro, em território norte-americano, em especial, estadunidense. Enxergar o mundo através de uma perspectiva da diferença em que se (re)lê as idiossincrasias dos povos, das culturas, das artes, das literaturas crivados na diversalidade epistêmica é o que faz de Silviano Santiago, atualmente, o maior representante da visada pós-colonial no Brasil. Por diversalidade, entendemos

[...] uma visada horizontalizada em que toma as diferenças dos sujeitos, culturas e lugares como quantitativas, para usar um termo próximo às diferenças qualitativas de diversidade, que tratam as diferenças alheias como características de especificidades particularizadas e que devem ser percebidas nas suas diferenças, não convergências; quantidade como sinônimo de múltiplas diferenças (BESSAOLIVEIRA, 2017, p. 52)

Pensar não mais único e exclusivamente da academia, mas sim, da cultura, do povo e, sobretudo, a partir do seu lócus geoistórico e epistemológico é o que difere o intelectual mineiro das plêiades de críticos brasileiros que, ainda hoje, se resguardam no discurso acadêmico engessado, cristalizado, polarizado e extremamente hegemônico. Discursos esses que replicam teorias itinerantes (BHABHA, 2014) as quais não levam em conta os loci de produção dos sujeitos, suas histórias locais, tampouco suas sensibilidades biográficas. $\mathrm{O}$ corpo, as histórias, os conhecimentos, os pensamentos, as artes desses indivíduos são rechaçados em detrimento a uma reverência aos discursos hegemônicos e coloniais que viajam dos centros para as margens e apagam tudo o que é da ordem da diferença colonial que 
toma a diferença como valor e a hierarquiza reforçando a colonialidade. Segundo Edgar Cézar Nolasco:

\begin{abstract}
Hoje, indiscutivelmente, Silviano é o maior representante de uma visada póscolonial no Brasil e um dos críticos brasileiros mais lidos nas discussões póscoloniais e subalternas latinas. Quero entender que tal mobilidade crítica encontrada na vivência crítica do intelectual se deu pelo fato de o crítico passear por várias tendências críticas, como a antropológica, por exemplo, e não ter medo de fazer grandes amizades nos trópicos, como a que estabeleceu com Derrida, Foucault e Lévi-Strauss (já convocados no ensaio de 78), entre outros. O "entre-lugar", escavado por Silviano para pensar a cultura (Literatura) brasileira e latina, permitiu que o crítico convocasse a crítica e os amigos que podiam ajudá-lo a compreender melhor nossa realidade brasileira latina. Essa mobilidade crítica, vivenciada pelo crítico brasileiro e que, a seu modo, corroborou uma descentralização crítica inerente à própria crítica brasileira [...] (NOLASCO, 2014, p. 19)
\end{abstract}

Nesse sentido, à luz dos postulados da Crítica biográfica fronteiriça (NOLASCO, 2015) que, em síntese, congrega os estudos pós-coloniais de Walter Mignolo (2003) e a crítica biográfica de Eneida Maria de Souza (2002) (2011), pretendemos, a partir do nosso lócus geoistórico e epistemológico fronteiriço sul-mato-grossense, engendrar uma discussão acerca da figura do intelectual (trans)fronteiriço Silviano Santiago na esteira de alguns conceitos, como desobediência epistêmica, opção descolonial e epistemologia fronteiriça.

Com base em uma metodologia de caráter eminentemente bibliográfico críticobiográfico fronteiriço e seguindo os conceitos supracitados faz-se possível delinear o perfil de um intelectual que se situa no espaço (trans)fronteiriço da literatura e dos saberes, uma vez que Silviano dilui as fronteiras entre ficção e ensaio propondo novas articulações ficcionaisteóricas fundamentadas em uma visada crítica homo-bio-ficcional. Que, tomando como base as reflexões de Gloria Anzaldúa em Borderlands: la frontera, essas articulações/loci não se encerram no plano geográfico, mas são psicológicas, sexuais e espirituais (ANZALDÚA, 2007, p. 35).

No plano da diferença, o crítico pós-colonial se preocupa com a colonialidade buscando, a partir das teorizações, ir na contracorrente do pensamento moderno. Seguindo a lógica descolonial, o crítico e intelectual fronteiriço, a partir da tomada de consciência do seu biolócus, se vale de conceitos como desobediência epistêmica e opção descolonial para sustentar uma epistemologia outra que não apenas reverencia as teorias itinerantes (BHABHA, 2014) que viajam dos centros para as bordas do planeta, mas se volta para as demasiadas fronteiras que atravessam seu corpo-político e que (de)marcam lugares epistemológicos também produtores de saberes, a exemplo, a fronteira-sul (Brasil/Paraguai/Bolívia) a qual vivemos e erigimos nossos discursos.

Diferentemente do que a narrativa moderna pretendia, a epistemologia pós-colonial volta seu olhar para as constituições identitárias que foram expurgadas ao esquecimento pelo 
sistema-mundo, tais como o corpo e as sensibilidades biográficas/locais. Walter Mignolo, por exemplo, articula que a produção do conhecimento é indissociável do seu lócus geoistórico. Nesse viés, as sensibilidades dos sujeitos fazem parte de suas histórias locais e, por sua vez, não podem e não devem ser marginalizadas e/ou esquecidas

Para Eneida Maria de Souza, em Janelas indiscretas (2011), Silviano Santiago é um dos agentes da consolidação e sistematização de um pensamento crítico brasileiro e, ademais, responsável pela formação de demasiados pesquisadores nacionais nas décadas de 1970 até os dias atuais. Desse modo, justifica-se a importância de discutir o papel e a representação de tal sujeito na crítica, cultura e literatura latino-americanas/brasileiras na atualidade. Propondo uma articulação entre a citação supracitada de Nolasco e as ponderações de Eneida sobre Silviano, percebe-se o impacto das produções, literárias e teóricas, do mineiro na formação intelectual, crítica e teórica brasileira. O papel desse intelectual (trans)fronteiriço se sobressai de modo contumaz quando (re)lemos seu caráter outro, pós-colonial crivado em uma óptica da desobediência epistêmica e da diversalidade, por excelência.

Por sujeito epistemicamente desobediente, entendemos o intelectual que por uma opção descolonial (MIGNOLO, 2003) buscou aprender a desaprender a razão imperial hegemônica exportada dos grandes centros mundiais e deglutidas pelas margens do planeta, como a fronteira-sul ao qual nos situamos e erigimos nossos discursos. O crítico pós-colonial, como Silviano por exemplo, aprende a desaprender para, enfim, reaprender sob a égide da diferença, propondo um pensamento outro que contemple as diversalidades, isto é, as diferenças vistas de maneira horizontal e não verticalizada/hierárquica como, ainda hoje, a academia reproduz. Silviano coloca em cena o conhecimento acadêmico hegemônico vis-à-vis ao popular, latino-americano, brasileiro não os hierarquizando, mas tomando-os pela diferença crítica. Nolasco corrobora:

[...] minha abordagem, entra em cena a "falsa obediência" percebida sagazmente por Silviano. "Falsa obediência" não significa falta de obediência; mas, pelo contrário, uma obediência outra, isto é, uma epistemológia fronteriza advinda do lócus geoistórico cultural latino, centrada numa opção descolonial. Enfim, com a "falsa obediência" [...] entrevejo uma lição crítica de fundo pós-colonial que convoca a todos para aprender a desaprender a lição crítica moderna cristalizada nos trópicos. Nesse sentido, entendo que Silviano não deslegitimou as ideias críticas europeias migradas para o Sul; mas, em contrapartida, não ficou preso a elas, repetindo-as acriticamente como tão comumemente aconteceu no Brasil e em toda a América Latina. (NOLASCO, 2014, p. 20)

Assentando-nos nas perspectivas da desobediência epistêmica e da opção descolonial, há que se refletir acerca da figura do especialista em literatura, especificamente, nos espaços geoistóricos e epistemológicos brasileiros. Como aposto, a academia ainda reproduz as teorias itinerentes (BHABHA, 2014) que não contemplam os loci de produção dos saberes, 
das artes, das literaturas. Sob esse prisma, o crítico palestino Edward W. Said na obra Representações do intelectual (2005) ressalta que, no geral, ser um especialista em literatura é excluir, de maneira significativa, a história, a música ou a política e se manter domesticado a aceitar qualquer discurso erigido dos grandes mestres (SAID, 2005, p. 81). No tocante às questões pós-coloniais, no ensaio, ainda não publicado, contudo, apresentado no "III Colóquio do NECC: entrelugares pós-coloniais” em 2014, Silviano afirma:

Vale dizer-, o afeto evita que me imunize com vacina. Com o corpo tomado por virose pós-colonial, torno-me febril e deliro. Instruído pelos intelectuais e escritores africanos e pela França, apaixono-me pela poesia de Aimé Césaire. Leio as revistas Temps modernes e Présence africaine e, marinheiro de primeira viagem, eu me escandalizo com a tomada do Teatro Odéon por tropa da OAS (Organisation de l'armée secrète) que decreta, no dia de estreia da peça, a proibição de Les paravents, de Jean Genet." (SANTIAGO, 2014, ensaio não publicado)

Silviano Santiago, conforme os debates de Said, seria um intelectual exilado em relação aos seus semelhantes que se mantêm estritamente uníssonos com os discursos hegemônicos colonizadores. O mineiro, devido aos trânsitos epistêmicos e artísticos que compõem seu bios, entendeu que o mundo não se aquilata em uma perspectiva polarizada, mas sim, do entre, do não lugar. E esse posicionamento se torna manifesto quando são produções críticas e ficcionais são (re)lidas segundo uma visada crítica outra, culturalista/póscolonial, que contempla a diferença não mais enquanto valor promovido pela colonialidade. Hugo Achugar, em Planetas sem boca (2006), propõe:

\footnotetext{
Aqueles que pensam que há somente um modo, ou somente uma via, para o trabalho teórico - a seu modo, ou o modo com que suas instituições definem como $a$ via não podem reconhecer o discurso do outro como estruturado e qualificado desqualificaram - como balbucio tudo o que eles interpretam como 'nãosistemático' e 'não-metódico'. Novamente, para que há um modo hegemônico ou 'prosperiano' de teorizar, e um outro modo canibal, subordinado, menor. (ACHUGAR, 2006, p. 38)
}

No que se relaciona à via ou às vias do trabalho teórico discutida por Achugar, Silviano Santiago, diferentemente de muitos críticos brasileiros, através de sua obra completa (ficção e teoria), explicita um posicionamento de caráter (trans)fronteiriço. Em suma, o intelectual ao passo que dialoga com a tradição ao eleger uma plêiade de amizades críticas composta por intelectuais brasileiros, latino-americanos e europeus (Clarice Lispector, Hugo Achugar ou Jacques Derrida, por exemplo) o mineiro dialoga também com o regional (não regionalista), com o contemporâneo ou, como Eneida Maria de Souza afirma em Janelas indiscretas, com o pop star cult.

Assim, trazendo ao plano pragmático, podemos identificar esse posicionamento na presença altamente politizada de Jacques Derrida e suas discussões sobre amizade política no romance Mil rosas roubadas (2014), a intersecção entre as artes plásticas de Lygia Clark e a 
literatura em Stella Manhattan (2017), da perspectiva outra que o mineiro lança-mão para narrar os últimos anos de vida de Machado de Assis no romance vencedor do Prêmio Jabuti Machado (2016), do recurso memorialístico autoficcional em $O$ falso mentiroso (2004), do uso do pastiche em Em liberdade (1981) ou dos debates sócio-políticos apostos no livro de poemas Crescendo durante a guerra numa província ultramarina (1988).

Já no que convém às obras de caráter estritamente crítico, podemos citar Nas malhas da letra (1989), Vale quanto pesa (1982), O cosmopolistismo do pobre (2004), Ora (direis) puxar conversa! (2006) e Uma literatura nos trópicos (2002), sendo estas compilações de ensaios que discutem literatura não apenas reverenciando a tradição e a academia, mas debatendo de modo crítico as produções artísticas enquanto objetos culturais em diálogo com temáticas outras, como a política, por exemplo. Em 2014, em Campo Grande, Mato Grosso do Sul, no "III Colóquio do NECC: entrelugares pós-coloniais", Silviano apresenta o ensaio "A literatura brasileira da perspectiva pós-colonial - um depoimento" reforçando sua opção descolonial e (re)verificando o posiciomento de grandes mestres da crítica literária brasileira, como Antonio Candido. Mais uma vez, não em reverência, mas assentado em um viés altamente crítico e pós-colonial. Assim, Denilson Lopes, em "Do entre-lugar ao transcultural" (2012) afirma:

Santiago recusa-se a ficar à sombra dos grandes mestres do passado, ser comentador bem comportado, evitando assim a canonização deles. Ele desloca o pensamento destes autores para fora de um cânone monderno e os faz vivos, atuantes, políticos. O entre-lugar, nesse sentido, poderia ser entendido em diálogo com o subalterno de Gayatri Spivak e com a poética de relação de Édouard Glissant. As três posições são estratégias marcadas por um entrecruzamento teórico e existencial semelhantes e situadas no cenário pós-colonial posterior à Segunda Guerra Mundial. (LOPES, 2012, p. 26)

Assim sendo, o livro de ensaios Uma literatura nos trópicos publicado no ano 2000, exemplifica de modo claro e objetivo as considerações supracitadas de Denilson Lopes sobre Silviano Santiago. A obra, grosso modo, é constuítuda de onze ensaios com foco, essencialmente, na dependência cultural da América Latina frente às grandes potências mundiais: Europa e Estados Unidos. Desde o título, o caráter latino-americano se faz presente; todavia, Silviano vai além e escava de maneira profunda as problemáticas que os latinos encontram em relação à diferença colonial tomada como valor pelo olhar do sujeito colonizador. Nesse cenário, refletindo sobre a civilização ocidental, o Novo Mundo e a América, Silviano corrobora:

Esse renascimento colonialista - produto reprimido de uma outra Renascença, a que se realizava concomitantemente na Europa - à medida que avança aproporia o espaço sócio-cultural do Novo Mundo e o inscreve, pela conversão, no contexto da civilização ocidental, atribuindo-lhe, pela conversão, no contexto da civilização ocidental, atribuindo-lhe ainda o estatuto familiar e social do primogênito. A 
América transforma-se em cópia, simulacro que se quer mais e mais semelhante ao original, quando sua originalidade não se encontrarian a cópia do modelo original, mas em sua origem, apagada completamente pelos conquistadores. Pelo extermínio constante dos traços originais, pelo esquecimento da origem, o fenônomeno de duplicação se estabelece como única regra válida de civilização. (SANTIAGO, 2000, p. 14)

$\mathrm{O}$ intelectual debate, ainda, temáticas que transitam desde críticas às teorias de fontes/influências desgastadas pela teoria da literatura em "O entre-lugar do discurso latinoamericano" (como supracitado), passando por obras de literatura brasileira, portuguesa e francesa em "Eça, o autor de Madame Bovary" e "O ateneu: contradições e perquirições", por música popular brasileira em "Caetano Veloso enquanto superastro" e encerrando com uma discussão acerca acerca do escritor francês Mallarmé em "O assassinato de Mallarmé". Silviano, em Uma literatura nos trópicos, já demonstrava sua característica (trans)fronteriça e pop star cult.

Diferentemente da maneira como a academia e, por sua vez, muitos intelectuais se posicionam, Silviano Santiago se coloca enquanto um crítico outro que não apenas referencia a tradição e as teorias viajantes. O mineiro, através de uma tomada de consciência do seu biolócus e crivado em um posicionamento desobediente epistemicamente e da ordem da opção descolonial, volta seu olhar para o seu lócus geoistórico e epistêmico buscando entender e discutir os engodos do seu próprio lugar de oridem discursiva, seja este espaço ficcional ou teórico. A cristalização do pensamento através de uma imersão academicista não se faz presente nos seus escritos. Dessa forma, Silviano, sobre a América Latina, reintera:

A maior contribuição da América Latina para a cultura ocidental vem da destruição sistemática dos conceitos de unidade e de pureza: este dois conceitos perdem o contorno exato de seu significado, perdem seu peso esmagador, seu sinal de superioridade cultural, à medida que o trabalho de contaminação dos latinoamericanos se afirma, se mostra mais e mais eficaz. A América Latina institui seu lugar no mapa da civilização ocidental graças ao movimento de desvio da norma, ativo e destruir, que transfigura os elementos feitos e imutáveis que os europeus exportavam para o Novo Mundo. (SANTIAGO, 2000, p. 16)

Portanto, à guisa de conclusão, como ressaltou Lopes em "Do entre-lugar ao transcultural", ler Silviano significa realizar uma política da diversidade, não se lê a favor, nem contra; mas entre (LOPES, 2012, p. 29). E isso possibilita todos os deslocamentos, movimentos, aproximações, distanciamentos, fidelidades, infidelidades tanto literários quanto, sobretudo, críticos tornando Silviano, dessarte, um intelectual (trans)fronteiriço haja vista a diluição de todas as fronteiras reais e imaginárias que o mineiro explicita, transborda, propõe e rompe.

Silviano cumpre seu papel enquanto intelectual ao quebrar os estereótipos e as categorias redutoras do penamento humano (SAID, 2005, p. 10) trazendo uma veia pós- 
colonial que, apesar dos avanços críticos, é rechaçada pela academia em detrimento da hegemonia dos saberes ainda imperante. Silviano, assim como Walter Mignolo e nós sujeitos fronteiriços pós-coloniais, deixa explícito que a sua opção é descolonial.

\section{Referências}

ACHUGAR, H. Planetas sem boca: escritos efêmeros sobre arte, cultura e literatura. Belo Horizonte: Editora UFMG, 2006. (Obra Completa).

ANZALDÚA, G. Borderlands/la frontera: the new mestiza. São Francisco: Aunt Lute Books, 2007. (Obra Completa).

BHABHA, H. K. O local da cultura. Trad. Myriam Ávila, Eliana Lourença de Lima Reis, Gláucia Renate Gonçalves. Belo Horizonte: Editora UFMG, 2013. 441 p. (Obra Completa)

BESSA-OLIVEIRA, M. Biogeografias como episteme local: fronteiras platinas (Brasil/Paraguai/Bolícia). In: . et al. Fronteiras platinas em Mato Grosso do Sul (Brasil/Paraguai/Bolívia): biogeografias na arte, crítica biográfica fronteiriça, discurso indígena e literaturas de fronteira. Campinas: Pontes Editores, 2017. (Capítulo de Livro)

LOPES, D. Do entre-lugar ao transcultural. In: . No coração do mundo: paisagens transculturais. Rio de Janeiro: Rocco, 2012. p. 21-46. (Capítulo de Livro)

MIGNOLO, W. Histórias locais/projetos globais: colonialidade, saberes subalternos e pensamento liminar. $1^{\text {a }}$ ed. Trad. Solange Ribeiro de Oliveira. Belo Horizonte: Editora UFMG, 2003. p. 505. (Obra Completa).

NOLASCO, E. C. Silviano Santiago e o lugar onde o sol se põe: entrelugares epistemológicos ao sul da fronteira-sul. In: CADERNOS DE ESTUDOS CULTURAIS. Silviano Santiago: uma homenagem. Campo Grande-MS: Ed. UFMS, v. 6, n. 11, jan./jun. 2014. p. 17-29. (Capítulo de Periódico)

SAID, E. W. Representações do intelectual: as conferências de Reith de 1993. São Paulo: Companhia das Letras, 2005. p. 127. (Capítulo de Livro)

SANTIAGO, S. Uma literatura nos trópicos: ensaios sobre dependência cultural. Rio de Janeiro: Rocco, 2000. (Obra Completa).

SANTIAGO, S. Luminosidades do observador. Disponível em: http://www.suplementopernambuco.com.br/edi\%C3\%A7\%C3\%B5es-anteriores/77capa/1651-luminosidades-do-observador.html. Acesso em 20 de jul. de 2018. (Artigo em Suplemento)

SANTIAGO, S. A literatura brasileira da perspectiva pós-colonial - um depoimento. (Ensaio não publicado)

SOUZA, E. M. de. Crítica cult. Belo Horizonte: Editora UFMG, 2007. p. 177. (Obra Completa) 
RELACult - Revista Latino-Americana de Estudos em Cultura e Sociedade

Revista Latinoamericana de Estudios en Cultura y Sociedad | Latin American Journal of Studies in Culture and Society V. 05, ed. especial, mai., 2019, artigo $\mathrm{n}^{\circ} 1456$ | relacult.claec.org |e-ISSN: 2525-7870

Janelas indiscretas: ensaios de crítica biográfica. Belo Horizonte: Editora UFMG, 2011. p. 261. (Obra Completa) 